\title{
Designing a new single-blade wind turbine using Computational Fluid Dynamics
}

\author{
$\underline{\text { S J Wakes }}^{\mathrm{a}}$, J Cornil ${ }^{\mathrm{b}}$ and B Currie ${ }^{\mathrm{c}}$ \\ a Department of Mathematics \& Statistics, University of Otago, Dunedin, New Zealand \\ ${ }^{b}$ Ecole Nationale, Supérieurs de Ingénieurs de Poitiers, Poitiers, France \\ ${ }^{c}$ Powerhouse Wind, Dunedin, New Zealand \\ Email: sarah.wakes@otago.ac.nz
}

\begin{abstract}
PowerHouse Wind, a small business in New Zealand, designs, develops and manufactures micro wind turbines for use on lifestyle property blocks. Their current design is rated at $2 \mathrm{~kW}$ at a rated wind speed of $10 \mathrm{~m} / \mathrm{s}$ and $315 \mathrm{rpm}$ and has a cut-in wind speed of $3 \mathrm{~m} / \mathrm{s}$ and a cut-out wind speed of $20 \mathrm{~m} / \mathrm{s}$. It has a unique one blade with teetering hub design that is specifically designed to cope with strong gusty winds. The wind turbine is soft-stalled to regulate power output with a variable rotation speed rotor that uses an electrical brake.
\end{abstract}

A combination of customer feedback as well as experience of New Zealand wind conditions has indicated a demand for a higher power rated turbine at $5 \mathrm{~kW}$. For a small business it is not necessarily an easy task to develop a new product as facilities for testing and multiple design iterations are often not available in house and can be expensive to outsource. An additional complication in moving from a $2 \mathrm{~kW}$ to $5 \mathrm{~kW}$ rated turbine is a variation on the current design is not possible as different airfoil families are recommended to maximise power output.

How then does a small enterprise design, develop and test a new highly complex engineering product? A build and test approach is only appropriate if time and money are not constrained or is only used to test the final configuration. Using numerical methods has advantages over a physical approach as multiple designs can be evaluated relatively easily. Fortunately for PowerHouse Wind their current blade design has been previously evaluated through numerical simulation and observational methods. Valuable insight had been gained into not only the performance of the current blade design in terms of power output and stall on the blade but also into the appropriateness and practicalities of using such methods to aid in the design of a new blade. This previous work on the existing Thinair 102 blade compared different simulation methods; less resource intense twodimensional methods; and a three-dimensional Computational Fluid Dynamics approach which is computationally expensive and requires expert users. It was found that when there was little stall on the blade the methods gave similar results. However, when stall was present on the blade, the two-dimensional methods overestimate the power output.

The design and development of the new blade therefore used a two-stage process. A two-dimensional blade design software, QBlade, was used to narrow the design envelope for the blade design in terms of position of the airfoil families, twist and chord length. Initial two-dimensional simulations were undertaken to ensure the new blade design generated reasonable lift (and therefore power) at the required optimum Tip Speed Ratio (TSR). A promising blade design was then selected for full three-dimensional CFD simulations across a range of appropriate wind speeds and rotor speeds. A detailed understanding of the relationship between the power output and stall behaviour with these parameters for the new blade design was established as a result that allowed PowerHouse Wind to evaluate the efficiency and effectiveness of this potential new blade design. This project has demonstrated that resource intensive state-of-the-art simulation methods such as CFD have a valuable role to play in new product design and development for small businesses. Care has to be taken to build on existing knowledge and be focused on what knowledge is required to progress the product development.

Keywords: Computational fluid dynamics, wind turbine, stall behaviour 


\section{INTRODUCTION}

\subsection{Background}

Utilising New Zealand's wind resource for energy generation is crucial to reach the New Zealand Government's goal of a low-emissions economy and incorporating provisions for small and community-scale renewable energy generation (2011). A one blade horizontal axis wind turbine (HAWT) has been designed and manufactured in New Zealand by PowerHouse Wind (Powerhouse Wind, 2013), especially for small-scale use on lifestyle properties. This stall regulated downwind turbine is rated at $2 \mathrm{~kW}$ with a $3.6 \mathrm{~m}$ rotation diameter and usually sits on an $8 \mathrm{~m}$ tower. The innovative turbine is designed to operate in strong gusty winds and has a teetering hub with a safe flag position to protect the blade. The controller adjusts the rotor speed of the turbine to initiate stall on the blade to brake the turbine and limit the power output within safe limits. This complex aerodynamic problem for this turbine has been studied using numerical simulations (two- and threedimensional) as well as some initial visualisation of flow on a working blade (Potonnier, Gabriel, Currie, \& Wakes, 2018; Wakes, Gabriel, Potonnier, Durbaum, \& Currie, 2017). The current blade design was found, from the simulations and confirmed by the visualization, to exhibit three distinct areas of stall with most of the power generation coming from the middle section of the blade (Potonnier et al., 2018; Wakes et al., 2017). It was seen that sudden changes in wind speed could produce large changes in power that have the potential to damage the turbine. This information can ultimately be used to optimise the controller algorithm to allow better responsiveness to these rapid changes in wind speed. This work also demonstrated that two- and threedimensional numerical simulation tools are useful tools in understanding stall on the blade and predicting power output over a range of wind and rotor speeds of the turbine. The two-dimensional simulations were found to overestimate power output from the turbine, particularly at higher wind and rotor speeds. Threedimensional Computational Fluid Dynamics (CFD) gave better predictions of power across the full range of wind and rotor speeds of the turbine and compared well with the measured data available. The braking of the blade due to stall was not predicted in the two-dimensional simulations. The stall/no stall patterns predicted on the blade were also seen to map to power generation along the blade. Although the CFD simulations are computationally more expensive, power predictions are more realistic and therefore useful for optimizing and fully understanding a new blade design.

PowerHouse Wind are interested in adding a $5 \mathrm{~kW}$ turbine optimised to a Tip Speed Ratio (TSR) of 7 as per the existing turbine, to their product range. Computational Fluid Dynamics was an obvious tool to use when designing a new blade to understand how the turbine behaves over a range of wind speeds and turbine RPM. Table 1 gives the specifications required by the new turbine blade design compared to the current

Table 1. New turbine specifications compared against the existing blade design

\begin{tabular}{|l|l|l|}
\hline Turbine Characteristic & Ideal Specification & Corrent \\
\hline Length & $\sim 2.4 \mathrm{~m}$ & $1.8 \mathrm{mn}$ \\
\hline Optinum TSR & 7 & 7 \\
\hline Alternator capacity & $5 \mathrm{~kW}$ & $2 \mathrm{~kW}$ \\
\hline Minimum wind speed & $10 \mathrm{~m} / \mathrm{s}$ & $10 \mathrm{~m} / \mathrm{s}$ \\
\hline Turbme type & HAWT & HAWT \\
\hline Rotor position & Downwind & Downwnd \\
\hline Power control & Soft stalled & Soft stall \\
\hline Maximum RPM & $<300$ rpin & $60-335$ rpm \\
\hline
\end{tabular}

an optimised blade with the best coefficient of power effectively and efficiently. For a small enterprise (SME) a trial and error approach based on physical prototyping and testing would be expensive and time consuming with no guarantee of an optimised final design. Although numerical testing methods have the potential to allow faster testing and optimization they can still be expensive and require specialist software and users (Fahey, Wakes, \& Shaw, 2008). This paper reports on work undertaken with an SME, Powerhouse Wind, to use threedimensional numerical CFD simulation software to design and test a wind turbine blade and asks whether using this approach is feasible for an SME.

\subsection{Blade Design}

The current Powerhouse Wind blade, Thinair 102 is part of a horizontal axis wind turbine (HAWT) that uses lift to generate the turbine power. The ideal Betz limit value for $\mathrm{C}_{\mathrm{p}}$ is $59 \%(0.59)$ for multi-blade lift-based turbines (Ragheb \& Rahheb, 2011),

$$
C_{p}=\frac{2 P_{\text {out }}}{\pi L_{\text {blade }}^{2} \rho_{\text {air }} v_{\text {wind }}^{3}}
$$


Tip Speed Ratio (TSR) is the ratio of the tangential speed of the tip of the blade to the speed of the wind. It is an important consideration for optimising blade design, with the current and new blade designed to a TSR of 7, which allows enough energy to be extracted from the tubine without generate too much drag,

$$
T S R=\frac{\omega_{\text {blade }} L_{\text {blade }}}{v_{\text {wind }}}
$$

where the rotational speed is $\omega_{\text {blade }}=\frac{2 \pi}{60} R P M, v_{\text {wind }}$ is the wind speed, $L_{\text {blade }}$ is the length of the blade, $\rho_{\text {air }}$ is the density of air, $\mathrm{T}$ is the torque and output power is $P_{\text {out }}=T \omega_{\text {blade }}$ (Ragheb \& Rahheb, 2011).

An open source two-dimensional wind turbine calculation software, QBlade, (Marten et al., 2014) was used for the initial blade design using the XFOIL/XFLR5 functionality. QBlade uses the aeroelastic code FAST

Table 2. Airfoil families used for existing and new blade

\begin{tabular}{|l|l|l|l|}
\hline Rotor Diameter & Root & Primary & Tip \\
\hline $1-3 \mathrm{~m}$ (Existing) & $\mathrm{S} 835$ & S833 & S834 \\
\hline $3-10 \mathrm{~m}$ (New) & $\mathrm{S} 823$ & S833 & S822 \\
\hline
\end{tabular}

(NREL, 2016) with BEM and other correction

algorithms for the simulation of the turbines. This two-dimensional simulation software is less resource intense than full three-dimensional CFD and therefore useful for initial blade design and optimisation. Table 2 outlines the NERL airfoil families, (Figure 1(a)), used for the existing (Figure 1(c)) and new blade design (Figure 1(d). The transition from $2.8 \mathrm{~kW}$ to $5 \mathrm{~kW}$ rated power output changes the recommended airfoils so a new blade design cannot be a scaled-up version of Thinair102. For the new design, the position, chord and twist needs to be determined along the blade. Utilising a stall optimisation algorithm yielded an initial blade (Figure 1(b)) but this blade had a low coefficient of lift at $\mathrm{TSR}=7$ and therefore low potential power output. A manual manipulation of the blade design resulted in the initial new blade design, (Figure 1(d)) used for testing using three-dimensional CFD code Fluent. The blade was imported into Solidworks for refinement and to create a geometry that could be used in the CFD software, ANSYS Fluent. A limited number of simulations for power output were also performed on QBlade for

(a)

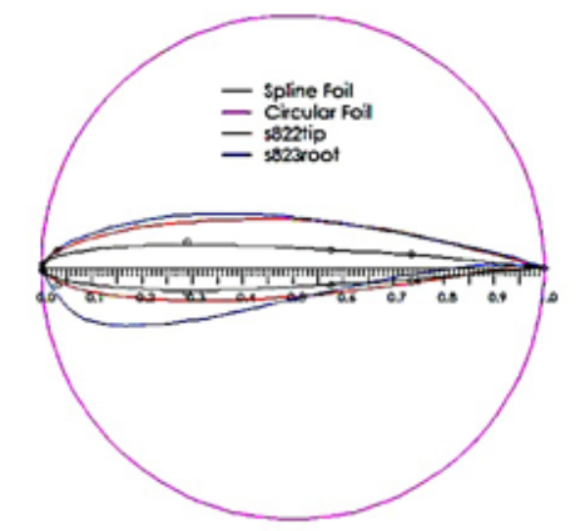

(c)

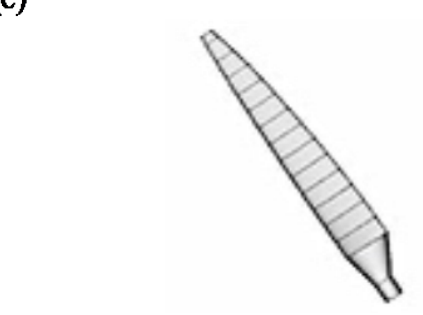

(b)

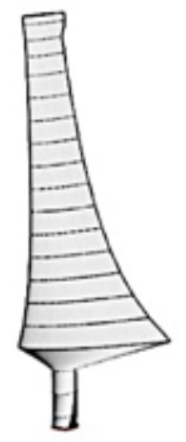

(d)

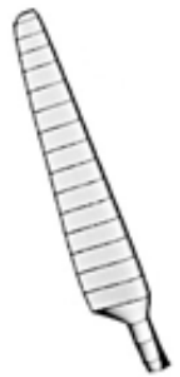

Figure 1. (a) NERL airfoil families used (b) first blade design optimised using QBlade (c) current Thinair 102 blade design and (d) new blade design for testing comparison with the CFD results.

\section{CFD SIMULATIONS}

The simulations in ANSYS Fluent followed the method in Wakes et al. (2017) with a final mesh after refinement of 10.5 million elements and using protocols from the standard NREL Unsteady Aerodynamics Experiment (Hansen \& Madsen, 2011). Only the blade and counter weights were modelled. The blades were kept stationary in a rotating cylinder of fluid emulating the rotating blade. A wind velocity was then imposed on the simulation. The SST $\mathrm{k}-\Omega$ turbulence model was used with SIMPLE and $2^{\text {nd }}$ order pressure and 
momentum discretization schemes (Wakes et al., 2017). Wind speeds in the range $9-20 \mathrm{~m} / \mathrm{s}$ with rotor speeds of 160-292 rpm were used.

\section{RESULTS AND DISCUSSION}

Figure 2 shows the comparison in Coefficient of Power (CoP) between QBlade (two dimensional) and CFD (three-dimensional) simulations for 13 and $18 \mathrm{~m} / \mathrm{s}$ wind speed over a range of TSR. Comparison between the two methods is better at the lower wind speed with a smaller difference between the results, with the highest difference seen at the lowest TSR. For the higher wind speeds QBlade predicted consistently much higher values of the power coefficient than the CFD simulations. It appears, as with other two-dimensional methods, that QBlade does not predict the stall on the blade with higher wind speeds and lower TSR (Wakes et al., 2017). The CFD simulations predict lower CoP values than the QBlade simulations when stall is present on the blade. For the higher values of TSR for a $13 \mathrm{~m} / \mathrm{s}$ wind speed the QBlade and CFD CoP predictions are more similar.

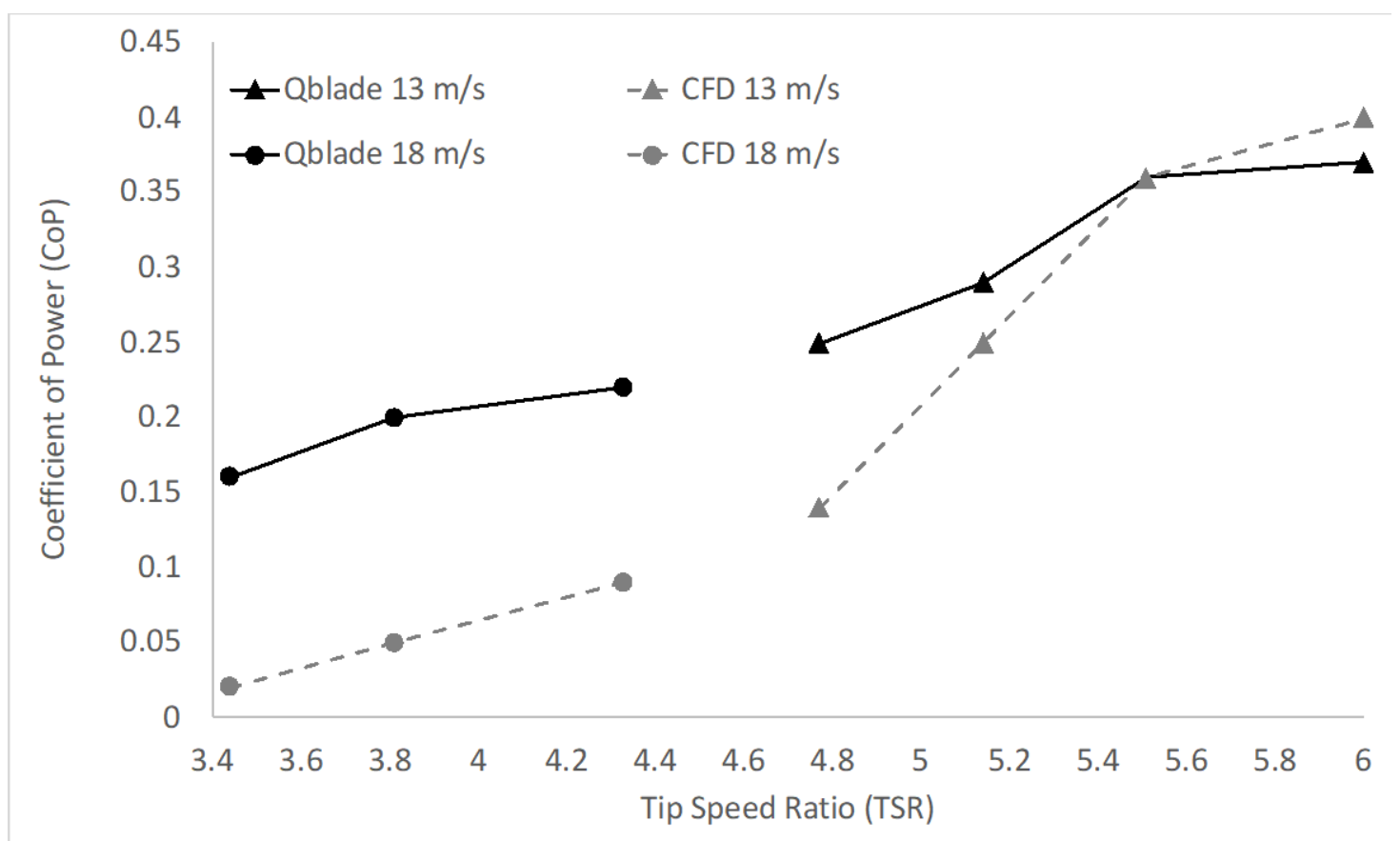

Figure 2. Comparison of Coeffient of power for Qblade and Fluent (CFD) simulations for $13 \mathrm{~m} / \mathrm{s}$ and 18 $\mathrm{m} / \mathrm{s}$ wind speeds

Figure 3 compares the flow pattern on the new blade at a wind speed of $13 \mathrm{~m} / \mathrm{s}$ for blade rotation between 232 and $292 \mathrm{rpm}$. Three areas of stall are visible at the lowest TSR, the tip, centre and along the leading edge. This stall pattern is broadly in line with that found for the current blade, Thinair 102, (Potonnier et al., 2018; Wakes et al., 2017) with some differences. This can be seen particularly around the stem of the new blade design where there is increased stall, although this should not affect power production significantly. The coefficient of power increases as rotor speed increases resulting in higher predicted power output from the blade. The power output can then be well above the rated capacity of the blade and signals that the rotation of the blade would have to be braked to prevent damage to the turbine components. Figure 4 compares four cases with $\sim 5$ $\mathrm{kW}$ power output. Two of these cases, at the lowest TSR, are heavily stalled with an inefficient coefficient of power. The two cases with the same rotor speed $(240 \mathrm{rpm})$ illustrate the effect of wind speed and stall. The reduction of wind speed from $13.5 \mathrm{~m} / \mathrm{s}$ to $11 \mathrm{~m} / \mathrm{s}$ increases power output by $0.71 \mathrm{~kW}(\sim 15 \%)$ and doubles the CoP. The blade in a wind of $13.5 \mathrm{~m} / \mathrm{s}$ has significantly more stall and illustrates the effectiveness of stall in limiting power output and how a responsive controller is crucial to manage variations in wind speed effectively with fast rotor speed response. Some of the cases have an increase in torque at around $1.4 \mathrm{~m}$ along the blade. This appears to be as a result of the recirculation pattern at this point, but more investigation maybe necessary. 
TSR

Radius [m]

\begin{tabular}{|c|c|c|c|c|c|}
\hline \multicolumn{6}{|c|}{\begin{tabular}{|l|l|}
1 & 1.5
\end{tabular}} \\
\hline & & & & & $\begin{array}{r}\text { Rator speed } \\
\text { Power } \\
C_{\mathbf{p}}\end{array}$ \\
\hline
\end{tabular}

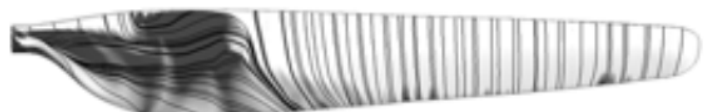

292 rpm

$11 \mathrm{~kW}$

0.4

5.51

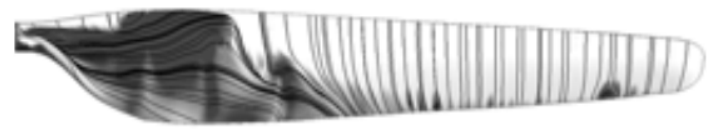

$268 \mathrm{rpm}$

$10 \mathrm{~kW}$

0.36

5.14

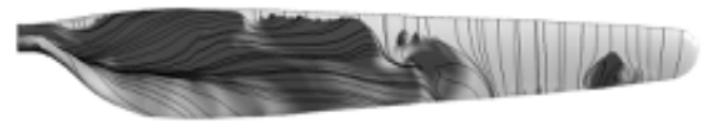

$250 \mathrm{rpm}$

$6.75 \mathrm{~kW}$

0.25

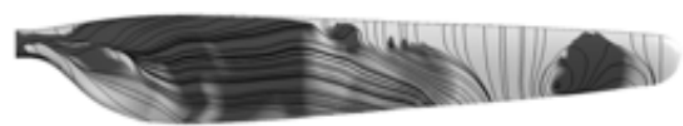

$232 \mathrm{rpm}$

$3.72 \mathrm{~kW}$

0.14

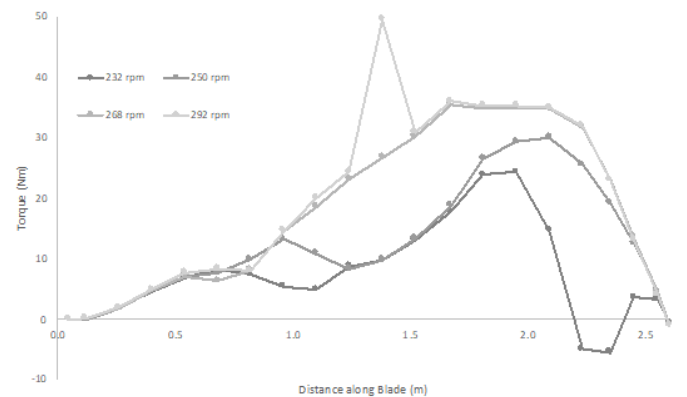

Figure $3.13 \mathrm{~m} / \mathrm{s}$ visualisation of stall on blade (dark areas reversed velocity with streamlines overlaid) comparing 4 TSR with associated RPM and predicted power and coefficient of power
TSR
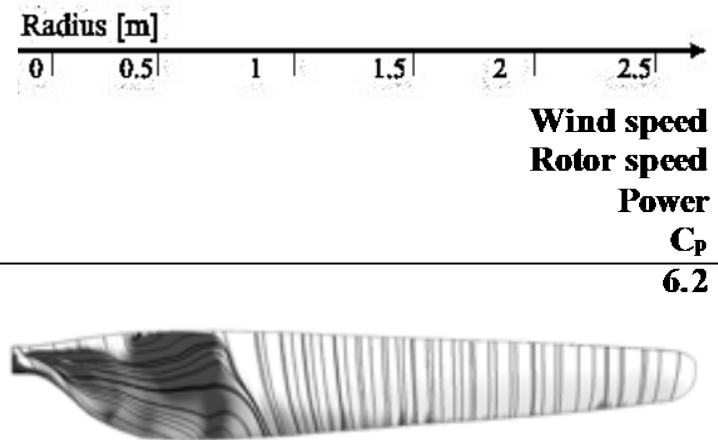

$10 \mathrm{~m} / \mathrm{s}$

$232 \mathrm{rpm}$

$5.92 \mathrm{~kW}$

0.42

5.83

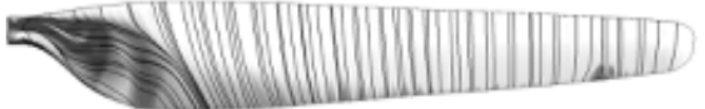

$11 \mathrm{~m} / \mathrm{s}$

$240 \mathrm{rpm}$

$5.52 \mathrm{~kW}$

0.33

4.75

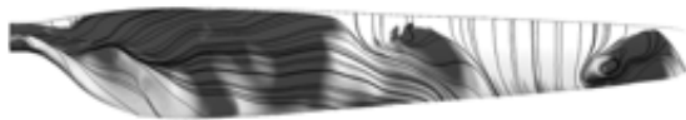

$13.5 \mathrm{~m} / \mathrm{s}$

$240 \mathrm{rpm}$

$4.81 \mathrm{~kW}$

0. 16

4.45

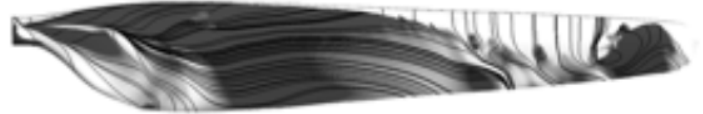

$15 \mathrm{~m} / \mathrm{s}$

$250 \mathrm{rpm}$

$4.58 \mathrm{~kW}$

0.11

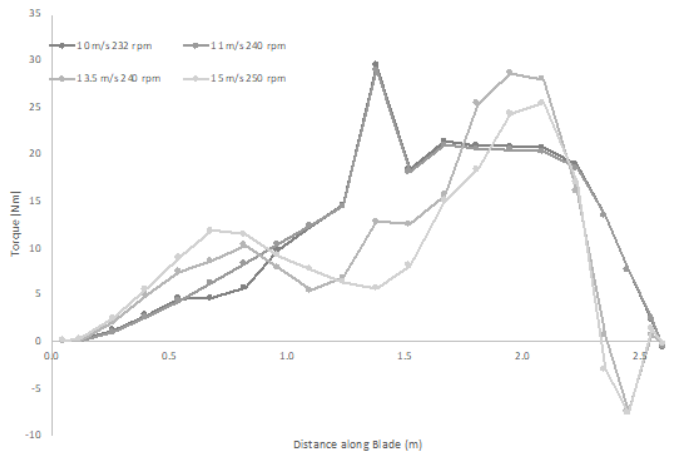

Figure 4. Comparison of stall patterns for power output prediction of $-5 \mathrm{~kW}$ 
In order to evaluate the performance of the new blade holistically and understand the potential for achieving the rated power output, power, rotor and wind speed are plotted on a surface (Figure 5). There are two areas for this blade that give the optimum rated power output of $5 \mathrm{~kW}$. In the wind speed range 9-11 m/s above 232 rpm there is minimum stall on the blade and power is in the order of $5 \mathrm{~kW}$ (area 1). When the wind speed is increased up to $13 \mathrm{~m} / \mathrm{s}$ the power output outperforms stall with the best CoP at $13 \mathrm{~m} / \mathrm{s}$. Above wind speeds of $13 \mathrm{~m} / \mathrm{s}$ the stall effect is more dominant than the torque and results in depletion of torque from the blade. Another area of optimum power is seen for wind speeds between 15.5 and $18 \mathrm{~m} / \mathrm{s}$ for rotor speeds in the range 272 to $292 \mathrm{rpm}$ (area 2). A least square fit surface quadratic equation for prediction of power output can be established from this surface plot. For this case this produces an average difference between the power predicted by this equation and the surface of $0.77 \mathrm{~kW}$. This simple equation and surface plot allow exploration of the performance of a new blade design across a wide range of wind speeds and rotor speeds as well as identification of potential problem areas (low or excessive power production for example)

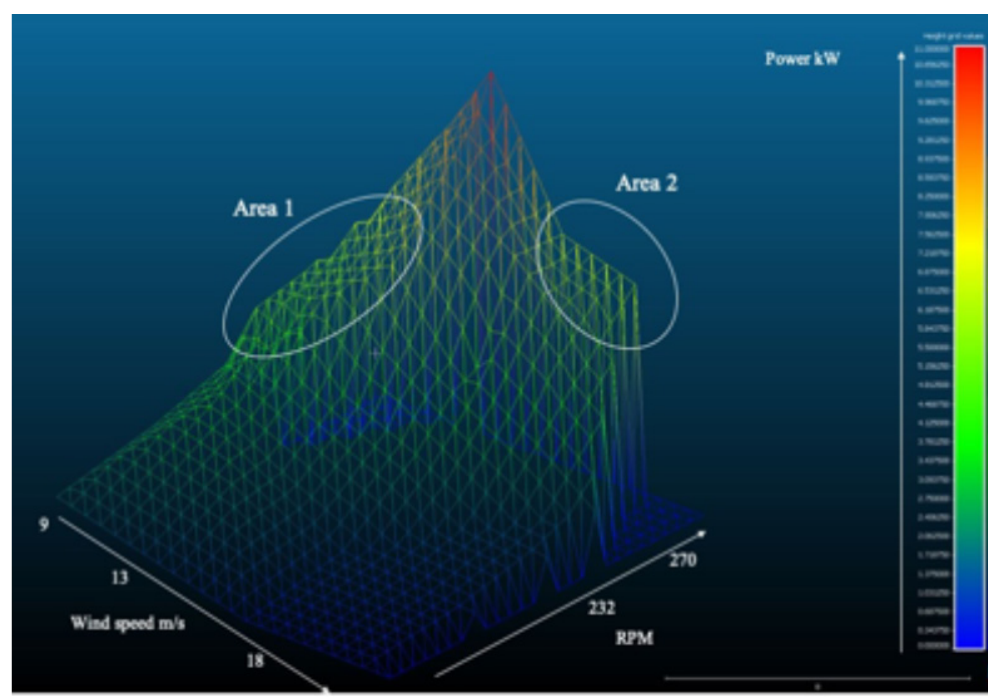

Figure 5. Surface plot of Power, RPM and wind speed that need to be addressed.

Another use of these surface plots is to gain insight into the comparison between the two- and threedimensional simulations (Figure 6(a)). By plotting the limited simulations carried out in QBlade with the CFD simulations results illustrates again that the two-dimensional method overpredicts power output for high wind speeds. These surface plots also allow easy visual comparison between blade designs. Figure 6(b) shows an example comparison between this current new blade design and one with a more twisted blade. Even though only five simulations with the twisted blade were carried out for this comparison it can be seen that the twisted blade has vastly decreased power output over the wind speed range of interest, signaling that this blade design is not worth pursuing.

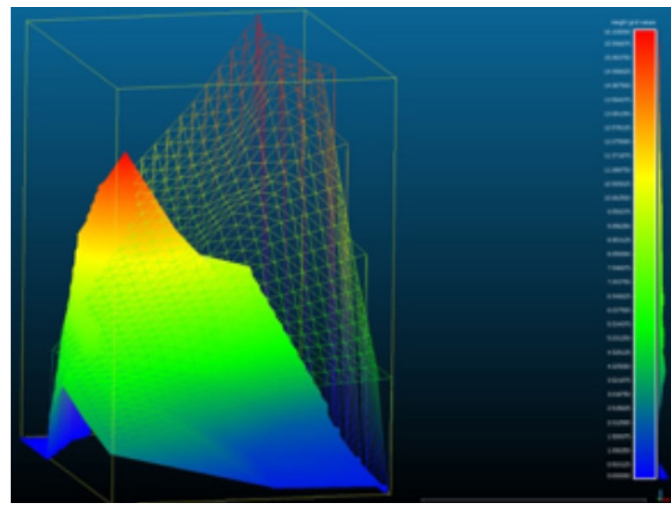

(a)

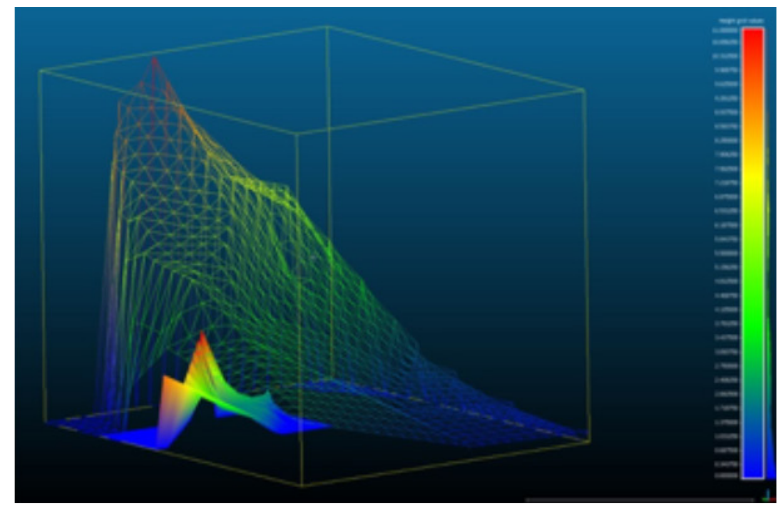

(b)

Figure 6. (a) Comparison between Qblade (solid) and Fluent (CFD, mesh) simulations and (b) Comparison of blades new (mesh) and more twisted (solid)

\section{CONCLUSIONS}

Following the successful use of Computational Fluid Dynamics simulations to better understand the role of stall in the control of power output from a unique one-blade micro turbine (Wakes et al., 2017), numerical 
modelling of a higher rated larger turbine blade has been undertaken. The aim of these simulations was to map power produced by a new blade design over the range of wind speed and blade rotation of interest. A twodimensional simulation package (QBlade) was used to initially design the new blade and do some initial power output simulations. It was found that there were differences between the two different simulation methods, especially when stall was present on the blade. This was usually at higher wind speeds when QBlade significantly overestimated the power output and the coefficient of power. The predicted performance of the blade would be oversold using only this method as it does not predict the role stall plays in braking the blade and therefore reducing power produced by the blade. Visualising the relationship between wind speed, rotor speed and power output allows easy understanding of the effectiveness of a new blade design and a tool to compare potential new blade designs if required.

For a small business it is not an easy task developing a new product, especially when performance is crucial to its success. Using tools such as CFD can help refine the design space (Bezerra \& Wakes, 2005) to minimise time and expense, as long as the criteria for optimisation of the design and decision making are explicit. Use of CFD was a more effective and efficient way of evaluating a new blade design for Powerhouse Wind than using a build and test method that is reliant on environmental considerations such as weather conditions and would take considerable resource and time commitment. Modelling the blade still requires investment in resources and people but has the potential to reduce development time significantly. However, enough threedimensional simulations within the envelope of operating parameters are required to ensure the power output surface generated is sufficiently detailed. The two-dimensional simulation methods, while they did not predict stall and overestimate power output, allow rapid triage of blade designs before they can be fully evaluated using CFD simulations. Building on existing knowledge and confidence from previous simulations had important role to play in maximizing the effectiveness of this technique for assessing a new blade design. For an SME, investment in commissioning a small number of CFD simulations would be a useful and feasible tool in refining a new blade design before physical prototyping and testing as demonstrated.

\section{REFERENCES}

Bezerra, C., \& Wakes, S. (2005, 29th May-1st June). Designing intellegence and the role of computersupported methods for innovation. Paper presented at the 6th International conference on computer-aided industrial design \& conceptual design, Delft, Netherlands.

Fahey, M., Wakes, S. J., \& Shaw, C. T. (2008). The use of CFD in oven design. International Journal of Multiphysics, 2(1), 37-57.

Hansen, M. O. L., \& Madsen, H. A. (2011). Review paper on wind turbine aerodynamics. Journal of Fluid Engineering, 133(11), 1-12.

Marten, D., Pechlivanoglou, G., Weinzireri, G., Wendler, J., Lennie, M., \& Moesus, N. (2014). QBlade (Version 0.8). Retrieved from http://www.q-blade.org

Ministry for the Environment. (2011). National Policy Statement for Renewable Electricity Generation 2011. Retrieved from https://www.mfe.govt.nz/publications/rma/nps-renewable-electricity-generation-2011

NREL. (2016). FAST. Retrieved from https://nwtc.nrel.gov/FAST

Potonnier, P.-Y., Gabriel, G., Currie, B., \& Wakes, S. J. (2018, 24-28 June). Stall behaviour of the Thinair 102 single-bladed wind turbine. Paper presented at the The 9th International Congress on Environmental Modelling \& Software iEMSs, Fort Collins, CO, USA.

$\begin{array}{lllll}\text { Powerhouse Wind. (2013). Thinair specification. } & \text { Retrieved from }\end{array}$ http://www.powerhousewind.co.nz/products.htm

Ragheb, M., \& Rahheb, A. M. (2011). Wind turbines theory - The Betz equation and optimal rotor tip speed ratio. In C. R (Ed.), Fundamental and Advanced Topics in Wind Power (pp. 19-38): INTECH.

Wakes, S. J., Gabriel, G., Potonnier, P.-Y., Durbaum, A., \& Currie, B. (2017, December 2017). Modelling a single-blade wind turbine using Computational Fluid Dynamics. Paper presented at the MODSIM2017, 22nd International Congress on Modelling and Simulation, Hobart, Australia. 